\title{
Clinical and Nutritional Assessment of Short Statured Indian Children with Celiac Disease
}

\author{
Mali LP', Meena SS ${ }^{2}$, Khatri PC ${ }^{3}$, Ram Kumar TV4, \\ Kumar $\mathbf{P}^{5}$ \\ ${ }^{1}$ Dr. Lalit P. Mali, MBBS, MD, Department of Paediatric \\ Medicine, Sardar Patal Medical College, Bikaner, India, \\ ${ }^{2}$ Dr. Shyam Sundar Meena, MBBS, MD, Department \\ of Paediatric Medicine, Sardar Patal Medical Collage, \\ Bikaner, India, ${ }^{3}$ Dr. Poonam Chand Khatri, Professor \\ and Head of Department, Department of Paediatric \\ Medicine, Sardar Patal Medical Collage, Bikaner, \\ India, ${ }^{4}$ Dr. TV Ram Kumar, MBBS, MD, Assistant \\ Professor. Department of Paediatrics, Great Eastern \\ Medical School, Srikakulam, India, ${ }^{5}$ Dr. Praveen Kumar, \\ Professor, Division of Paediatric Gastroenterology, \\ Department of Paediatric Medicine, Lady Hardinge \\ Medical College, New Delhi, India.
}

\section{Introduction}

hort stature (SS) is one of the common causes for $\checkmark$ referrals to paediatric endocrinologists ${ }^{1}$. In recent studies, celiac disease (CD) was considered to be a more common cause of short stature in otherwise healthy children than growth hormone deficiency ${ }^{2,3}$. Celiac disease $(C D)$ is an autoimmune enteropathy occurring in genetically susceptible individuals (HLA DR3, DR4, DR5, DR7) and is triggered by the ingestion of gliadins contained(ing) food. It is typically characterized by diarrhea, malabsorption, anemia, wasting and stunting ${ }^{4}$. When compared with well-nourished and genetically relevant population, short stature is defined as height or length below 3rd percentile for that age and gender ${ }^{5}$. Short stature is a well-known feature of paediatric celiac disease and is reversible to a large extent if put on strict gluten free diet. CD is reported in about $2-4.7 \%$ of short stature patients ${ }^{6,7}$. Celiac disease not an uncommon condition in India. Diagnosis and meticulous dietary management of celiac disease is mandatory since wheat is staple diet in North-west states of India including Rajasthan.

\begin{abstract}
Introduction: Celiac disease is an autoimmune disease, which is increasingly recognized as a cause of short stature in genetically susceptible population. The present study was undertaken to look for prevalence of celiac disease among the pediatric population with short stature (SS) and to study characteristics of these short statured children with celiac disease. Materials and Methods: This is a prospective study conducted at a tertiary teaching hospital at Bikaner, Rajasthan to look for the occurrence of celiac disease amongst the pediatric population ( $\leq 15$ years) with short stature $(n=100)$. Other common causes of short stature were also identified. Results: Out of 100 short statured children, $38(38 \%)$ had celiac disease and other major causes responsible were hypothyroidism, pituitary disorders, constitutional growth delay, and familial short stature. Chronic diarrhea, anorexia, anemia and behavioral changes were statistically more common in short statured children ( $\leq 15$ years) having celiac disease than non celiac patients. Conclusion: We conclude that celiac disease is not an uncommon cause of short stature and stunted growth in this region. All short statured patients should be screened for celiac disease.
\end{abstract}

Key words: Celiac disease (CD), Short stature, Gluten enteropathy

\section{Materials and Methods}

This qualitative study was conducted during 20072008 in the Department of Paediatrics in collaboration with Department of Gastroenterology and Microbiology, Sardar Patel Medical College and Associated Group of Hospitals, Bikaner (Rajasthan) a tertiary care teaching hospital, western India. The departmental ethical committee approved this study. The patients attending both in outpatient (either as general or gastro-special) or inpatient for short stature evaluation or were seen to have SS during clinical examination were enrolled for study

\footnotetext{
How to cite this article?

Mali LP, Meena SS, Khatri PC, Ram Kumar TV, Kumar P. Clinical and Nutritional Assessment of Short Statured Indian Children with Celiac Disease. J Nepal Paediatr Soc 2013;33(2):91-94.
}

\author{
Address for correspondence \\ Dr. TV Ramkumar \\ Department of Paediatrics \\ Srikakulam, India \\ E-mail: starringram@gmail.com
}

This work is licensed under a Creative Commons Attribution 3.0 License. 
after obtaining written consent. A history of any chronic illness, constipation, delayed milestones, perinatal events was obtained. In all of these children height was taken by the physician using stadiometer (or Seca wall mounted system, with a vertical plate fixed to wall at a measured height, and a movable horizontal plate. It contains a tape and the reading is taken at redline) with a least count of $0.1 \mathrm{~cm}$ and was monthly calibrated for accuracy. Short stature cases were identified on the basis of anthropometric measurements as per National Council of Health Statistics (NCHS) standards ${ }^{8}$. The cases having stature below $3^{\text {rd }}$ percentile were labeled as short stature. Then, the height of parents was obtained, and mid-parental height calculated. The target height and target range was plotted on the growth chart. Then bone age was estimated by ATLAS by taking an $x$ ray of left hand ${ }^{9}$. Other anthropometric parameters including upper segment:lower segment ratio, arm span, any obvious dysmorphism were mentioned. A thorough systemic examination was done to look for systemic causes of short stature. The children were then subjected to a tier of investigations to look for possible causes. As a baseline, children were investigated with basic blood investigations (hemoglobin, total and differential counts), liver enzymes, random blood sugar, serum creatinine, TSH, T4 levels, anti tTG, urine and stool routine examination. The anti tTG levels (IgA anti tissue transglutaminase) were quantitatively estimated by ELISA with a cut-off of $>20$ IU. The Celiac tTG IgA (ImmuLisa ${ }^{\mathrm{TM}}$ ) enzyme-linked immunosorbent assay (ELISA) kit was used for quantitative determination, as per the manufacturer's instructions. The duodenal biopsy was performed in all abnormal tTG children, and clinically CD with normal tTG levels. A diagnosis of celiac disease was made as per modified ESPGHAN criteria $^{10}$. The children with moderate or severe duodenal mucosal changes (Marsh type 2 and 3) were included in this study ${ }^{11}$. In cases of clinical suspicion, Clonidine stimulated (sex steroids primed in peripubertal patients) GH assay was done. In some of female cases, karyotyping was done to exclude Turner syndrome. The clinical and nutritional profile of short statured children ( $\leq 15$ years) with or without celiac disease were compared. The data were analyzed by Epi Info (3.4.3 version) software. All continuous parametric variables were compared by using t-test and all non-parametric variables by Mann-Whitney test. All categorical data were analyzed by chi-square/Fisher's exact test. A probability of $5 \%$ was considered significant.

\section{Results}

There were 100 patients which included 57 males $(57 \%)$ enrolled in the study. The prevalence of celiac disease (CD) among the sample population was $38 \%$ $(n=38)$. Thyroid evaluation was done in all patients, TSH was abnormally high $(>10 \mathrm{mlU} / \mathrm{ml})$ in 19 children, and $\mathrm{GH}$ levels were low $(<10 \mathrm{ng} / \mathrm{ml})$ in 9 patients of 19 tested patients. There were two children of Turner syndrome (Karyotyping done in five cases only). There were three children with gross rickets and bone deformity, and two had achondroplasia. Liver enzymes were abnormal (>2 times elevated) in 15 cases (SGOT in 13 and SGPT in 10) of celiac disease. There were 8 cases of congenital heart disease (4 with tetralogy of Falot, and 3 with VSD and uncontrolled congestive heart failure). There were 5 cases of chronic kidney disease ( 3 steroid resistant nephritic syndrome and 2 steroid dependent) and 2 cases of type 1 diabetes mellitus.

The mean ages at onset of presenting symptoms and at diagnosis of $C D$ in short statured children in hospital were 2.6 (range 1.3-12) years and 6.38 (range 3.5-15) years respectively. Out of the total 38 , maximum numbers were diagnosed in the age range $6-10$ years $(22,58 \%)$. Diarrhea and anorexia symptoms were more common in celiac patients as compared to non-celiac patients and the difference was statistically significant ( $p$-value 0.01$)$. Anaemia $(84.21 \%$ ) was the most common extra-intestinal manifestation of $C D$ in short stature patients followed by behavioural changes $(26.31 \%)$, hair changes $(10.52 \%)$, hyperpigmentation of skin $(10.52 \%)$ and edema (7.89\%) (Table I). However, the mean haemoglobin $(\mathrm{Hb})$ values did not vary much among the short statured CD patients $7.55 \pm 2.4$ (gm $\%)$ and non-celiac short patients 7.62 \pm 3.22 (gm \%); statistically insignificant ( $p$-value 0.91 ).

Table 1: Clinical features of short stature (SS) patients with and without celiac disease (CD).

\begin{tabular}{|l|c|c|c|}
\hline Clinical feature & SS with CD (n=38) & SS without CD (n=62) & p-value \\
\hline Diarrhea & $24(63.15 \%)$ & $14(22.5 \%)$ & $0.01^{*}$ \\
\hline Anorexia & $12(31.57 \%)$ & $6(9.67 \%)$ & $0.01^{*}$ \\
\hline Pain abdomen & $10(26.31 \%)$ & $10(16.12 \%)$ & 0.22 \\
\hline Excessive appetite & $6(15.78 \%)$ & $4(6.45 \%)$ & 0.13 \\
\hline Anemia & $32(84.21 \%)$ & $44(70.96 \%)$ & 0.13 \\
\hline Behavioral changes & $10(26.31 \%)$ & $2(3.22 \%)$ & $0.01^{*}$ \\
\hline Hair changes & $4(10.52 \%)$ & $2(3.22 \%)$ & 0.13 \\
\hline Hyperpigmentation of skin & $4(10.52 \%)$ & $4(6.45 \%)$ & 0.46 \\
\hline Edema & $3(7.89 \%)$ & $6(9.67 \%)$ & 0.34 \\
\hline Rickets & 0 & $2(3.22 \%)$ & 0.13 \\
\hline
\end{tabular}




\section{Discussion}

Short staure (SS) imposes disability and can be a distress to the victimised child or adolescent and treatment is effective if given before epiphyseal fusion $^{12}$. Celiac disease is an important cause of short stature in some geographical areas. So, SS should be assessed early to get the opportunity of medical management. Celaic disease effects growth secondary to malabsorption, impaired growth hormone release, and association with autoimmune hypothyroidism. In the present series, out of total 38 celiac proved short statured children, 14 children $(36.84 \%)$ had no diarrhoea; they presented with growth retardation, anaemia. A higher proportion of cases (20-40\%) did not have diarrhoea in western studies ${ }^{13-15}$. This may suggest that, in our country, patients with celiac disease without diarrhoea may not seek medical treatment, and they remain undiagnosed ${ }^{16}$. Bhadada SK et al study on 176 children with short stature from Chandigarh, celiac disease was found in $27(15.3 \%)$ of the patients, so that celiac disease was the single most common cause of short stature, 25 children (14\%) had pituitary disorder, 24 had (14\%) hypothyroidism, and constitutional delay of growth and puberty or familial short stature accounted for $18(11 \%)$ patients ${ }^{17}$. Other less common causes of short stature were metabolic bone disease, Turner syndrome, adrenal disorders, diabetes mellitus, and nutritional deficiency. In previous studies done in India, its prevalence varied from 13.7 to $20.5^{18-19}$. In the present study, the higher prevalence of $C D$ in short statured children might be differences in the prevalence of CD in study populations. As in present study, the presence of chronic diarrhea, and decreased appetite increases the probability of short stature patients ( $p$ value 0.01 ). However, present study has limitations attributed to the small sample size. The authors recommend for a larger study with response to gluten free diet amongst CD children with short stature.

\section{Conclusion}

Celiac disease is an important cause of short stature (38\% of children with SS) in north India. We propose all growth retarded children should be screened for celiac disease irrespective of gastrointestinal symptoms as well as periodic review of etiology of short stature. Early diagnosis and gluten free diet has the good outcome in short stature children.

Acknowledgements: None

Funding: Nil

Conflict of Interest: Nil

Permission from IRB: Yes

\section{References}

1. Lam WF, Hau WL, Lam TS. Evaluation of referrals for genetic investigation of short stature in Hong Kong. Chin Med J (Engl) 2002;115:607-11.

2. Cacciari E, Salardi S, Volta U, Biasco G, Lazzari R, Corazza GR, et al. Can antigliadin antibody detect symptomless coeliac disease in children with short stature? Lancet 1985;1:1469-1471.

3. Cacciari E, Salardi S, Lazzari R, Cicognani A, Collina A, Pirazzoli P, et al. Short stature and celiac disease: a relationship to consider even in patients with no gastrointestinal tract symptoms. J Pediatr 1983;103:708-711.

4. Di Sabatino A, Corazza RG: Coeliac disease. Lancet 2009;373:1480-1493.

5. Rogol AD. Causes of short stature. In: Rose BD, (edi). Up-todate 15.1 [CD Rom]. Waltham MA: upto-date; 2007.

6. Pasquino AM, Albanese A, Bozzola M, Butler GE, Buzi F, Cherubini V, Chiarelli F, Cavallo L, Drop SL, Stanhope R, et al. Idiopathic short stature. J Pediatr Endocrinol Metab 2001;14 Suppl 2:967-974.

7. Queiroz MS, Nery M, Cancado EL, Gianella-Neto $D$, Liberman B. Prevalence of celiac disease in Brazilian children of short stature. Braz J Med Biol Res 2004;37:55-60.

8. Hamil PW, Drizd TA, Johnson CL, Reed RB, Roche AF, Moore WM. Physical growth: National Centre for Health Statistics percentile. Am J Clin Nutr 1979;32:607-29.

9. Gilsanz V, Ratib O. Hand Bone Age: A Digital Atlas of Skeletal Maturity. Germany: Springer;2005.

10. Working Group of European Society of Pediatric Gastroenterology and Nutrition. Revised criteria for diagnosis of celiac disease. Arch Dis Child 1990;65:909-11.

11. Marsh M. Gluten, major histocompatibility complex and the small intestine. Gastroenterology 1992;102:330-54.

12. Kemp S. Short stature and growth failure. Department of Pediatrics, Section of Pediatric Endocrinology, University of Arkansas and Arkansas Children's Hospital, 2007;150-6.

13. Bottaro G, Failla P, Rotolo N, Sanfilippo G, Azzaro F, Spina $M$ et al. Changes in coeliac disease behaviour over the years. Acta Pediatr 1993;82:566-8.

14. George EK, Jansen TLTA, Mearin ML, Mulder CJJ. Epidemiology of celiac disease in the Netherlands. J Pediatr Gastroenterol Nutr 1997;24(Suppl 1):S79. 
15. Ascher H, Holm K, Kristiansson B, Mäki M. Different features of celiac disease in two neighbouring countries. Arch Dis child 1993;69:374-80.

16. Kumar M, Yaccha SK, Naik SR. Celiac Disease in children. Indian J Gastroenterol 1993;12:A15.

17. Bhadada SK, Bhansali A, Kochhar R, Menon AS, Sinha SK, Dutta $P$, et al. Does every short stature child need screening for celiac disease? J Gastroenterol Hepatol 2008;23:353-6.
18. Bhadada SK, Bhansali A, Ravikumar P, Kochhar $R$, Nain CK, Dutta $P$, et al. Changing scenario in aetiological profile of short stature in India-growing importance of celiac disease: a study from tertiary care centre. Indian J Pediatr 2011;78(1):41-44.

19. Ahmad F, Alam S, Shukla I, Sherwani R, Ali SM. Screening children with severe short stature for celiac disease using tissue transglutaminase. Indian J Pediatri 2010;77(4):387-390. 